\title{
How to Expand Subway and Urban Railway Networks: Light Rail Extensions in Madrid, Spain.
}

By: Juan de Oña, Francisco J. Calvo, Laura Garach, Rocío de Oña, and Griselda López

This document is a post-print versión (ie final draft post-refereeing) of the following paper:

Juan de Oña, Francisco J. Calvo, Laura Garach, Rocío de Oña, and Griselda López (2010) How to Expand Subway and Urban Railway Networks: Light Rail Extensions in Madrid, Spain. Transportation Research Record: Journal of the Transportation Research Board, 2146, 10-17.

Direct access to the published version: http://dx.doi.org/10.3141/2146-02 


\title{
How to Expand Subway and Urban Railway Networks: Light Rail Extensions in Madrid
}

\author{
Juan de Oña*, Francisco J. Calvo, Laura Garach, Rocío de Oña and Griselda López \\ TRYSE Research Group, Department of Civil Engineering, University of Granada \\ *Corresponding Author: ETSI Caminos, Canales y Puertos, c/Severo Ochoa, s/n, 18071 Granada \\ (Spain), Tel: +34958 249979, e-mail:jdona@ugr.es
}

Word Count: 4885 (text) $+5 \times 250$ (tables) $+5 \times 250$ (figures) $=7385$ words

\begin{abstract}
Residential areas consisting of detached houses were built in North and East Madrid during the last decade of the twentieth century. This implies that the population density in those areas is very low and, therefore, implementing an efficient transport system is complicated. In South Madrid in the 60s, however, huge commuter towns developed. Some of them were linked to a suburban network at some point, while others were very far away.

The Madrid region promoted the construction of several light rail lines to resolve the issue. The lines function as extensions to the existing rail network (subway or suburban trains). This article describes those lines and analyses the determining factors that enabled them to be implemented and operated successfully. The recommendations for implementing a LRT System, based on that analysis, are: the lines should not be very long; they should have a segregated right-of-way; the quality of service should be good, and they should be coordinated with other modes of transport. Apart from public funding, they could be funded by additional resources collected from property tax and the concessionaire company (private funding). A concessionaire consortium may comprise construction companies, transport operators, financial institutions, rolling stock manufacturers and consultancies. Finally, the concession should be granted for a 30 to 40 -year period so private stakeholders can recover their investment.
\end{abstract}

\section{KEYWORDS}

Metropolitan mobility; light rail transit; operation; funding; Madrid 


\section{INTRODUCTION}

Probably the main difference, if any, between a tramway and a light rail transit (LRT) system is the "segregated right-of-way". This new concept appeared when it was recognized that the traditional tram had reached its limit and that the solution was not to replace it, but to protect and develop it, giving it the space it required. The LRT system developed in its current form at the end of 1960s in medium-sized cities in Germany. In the 1970s this development continued slowly in cities with a major tram network and, in the 1980s, cities that had completely lost their trams, as Madrid, decided to implement new LRT lines.

In Madrid, the tramway system implemented in 1871 was initially animal-powered. The services were operated by private companies funded by foreign capital. The lines were electrified in 1900 . The first underground line, opened in 1919, was also funded with private capital. Subsequently, the new network expanded and began to compete with the tramway system. In 1948, the tramway network became part of the Empresa Municipal de Transportes (EMT) (municipal transport company), which also set up the city bus system. The longest extension of the Madrid trams in 1954 was $188 \mathrm{Km}$. Shortly after their heyday, the trams were shut down, beginning with the trams in the city's old quarter and ending with the closing of the last line in 1972. Only 13 years later the Madrid City Council decided to implement the tramway system again. It was found to be a valuable tool for the mobility issues facing the public transport system.

The reserved space at ground level separates the LRT from private vehicles, but enables levelcrossing with pedestrians and other traffic (see Figure 1). Thus, it fits easily into the urban landscape, which is usually renovated at the same time. The majority of new LRT system developments are accompanied by a renewal of the city areas en route, which reinforces the potential of urban transformation. This enables run-down areas to be regenerated, and has a great impact on the urban landscape through the conversion of old railway lines and facilities, and through the expansion of the network to the city's historical areas (1).

The space for the LRT should be exclusively reserved throughout the entire track length in order to increase its speed and regularity. Part of the existing lines should be used, thereby limiting the capacity for private vehicles while increasing the capacity for public transport and mobility along the entire system. The restriction of privately-owned vehicles, combined with the benefits of enhanced public transport, also serves to "educate" citizens so they will become accustomed to sustainable transport in a sustainable city.

The new concept also includes the use of new vehicles (see Figure 1) with a modern design and features -a low floor for easy access-, and the use of new technology that allows priority at junctions with traffic lights, real time information, and other advantages. As a result, the new LRT lines emerge as new infrastructure for the city, and also as a key aspect for a sustainable mobility policy that promotes environmentally friendly methods of transport, such as public transport, biking and walking. Downtown access by car is restricted, as in Strasburg (since 1994), or even completely off limits for private vehicles.

Today, there are some 400 systems in operation worldwide, with constructions in some 60 more and plans in well above 200. Europe is the densest LRT continent with 170 systems in operation and nearly 100 more in construction or planned (see Table 1). North America (30 in operation, 10 in construction) and Asia are also very active in opening new systems (2).

As in other European countries, Spain is developing light rail systems in many medium-sized cities where only bus systems exist (A Coruña, Alicante, Murcia, Malaga, Granada, Vitoria and Tenerife, for instance). However, LRT systems are also being set up in big cities such as Madrid, Barcelona and Seville to complement the existing public transport systems and extend them to outlying and more lightly populated areas where fully independent infrastructure (subways, suburban railway lines) are not profitable due to the low demand.

This article describes the experiences in implementing the new LRT lines recently undertaken in the region of Madrid (Spain) to extend the public transport system to the city suburbs. The following section gives a brief description of the characteristics of mobility management in public transport in the Madrid region. The next section gives a detailed description of four new LRT lines that have been in 
operation since 2007, and of the plans for two new lines that are under way. The section approaches the topics of the characteristics of LRTs, connectivity between lines, intermodal connectivity with subway and suburban railway networks, fare integration, organization structure, operations service patterns and new funding systems. The final section presents conclusions and recommendations.

\section{LRT: A SOLUTION FOR MOBILITY TO MADRID'S SUBURBS Population and mobility in the Madrid region}

The Madrid region covers an area of $8,028.5 \mathrm{sq} \mathrm{km}$. The population in 2007 was 6.27 million, with an average population density of 781.2 per sq $\mathrm{km}$. Table 2, however, shows a considerable difference between the population density in Madrid City (Zone A) and the outlying towns (Zones B and C).

The important differences in population densities (from pop. 5,298.9 per sq $\mathrm{km}$ in Madrid City to pop. 83.6 per sq $\mathrm{km}$ in Zone $\mathrm{C}$, the one furthest away), the functional dependency of most towns on Madrid, and the eminently radial nature of the suburban public transport network are the main reasons that justify the mechanized mobility distribution shown in Table 3 .

Table 3 shows that, on the whole, mobility is divided 50/50 between public and private transport. Whereas in Madrid City public transport represents $64 \%$ of mechanized mobility, however, mobility in the rest of the region is below the average. Public transport is within the average for travel between Madrid City and the rest of the region. Currently, one of the principal concerns of Madrid's regional transport consortium (Consorcio Regional de Transportes de Madrid, or CRTM) is to enhance the service so the public transport distribution in the Madrid region (Zones B and C) will be higher. This is one of the reasons for implementing the new LRT lines in those zones.

The CRTM comprises all the public transport authorities in the Madrid region: Ministry of Public Works (national government), Madrid regional government, and municipal administrations. The CRTM's main functions are to:

- Plan public transport infrastructures,

- Set up a comprehensive fare system for the whole public transport network,

- Plan and coordinate services and programs for the operation of all transport modes (suburban railway, subway, EMT city buses, other public city buses, suburban private buses and LRT), and

- Create an overall image of the public transport system, where the CRTM handles the external relationships with public transport users.

Table 4 shows the public transport supply and demand in the Madrid region in 2008. In Madrid City (Zone A), 70\% of the demand for public transport was covered by the Metro network (43\%) and the city buses (27\%). Whereas the Metro network and the suburban railways show the highest demand/supply, the ratios for buses are very low. The new LRT lines, described in detail in the following section, show a high demand/supply ratio, close to that of the suburban railway and four times higher than the city buses in Zone A. Therefore, the utilization of railway (or guided) modes of transport is much higher than the utilization of buses.

\section{NEW LIGHT RAIL LINES IN MADRID REGION}

This new concept of transport was proposed for Madrid for the first time in 1985. The Madrid General Urban Plan envisaged four LRT lines that were never implemented. It was not until the 2003-2007 period that this new mode of transport finally became a reality.

During this period, the Madrid regional government built and opened 4 LRT lines, covering 36 $\mathrm{km}$ (see Table 5). All the LRT lines are included in the autonomous region of Madrid's fare structure, so transport tickets and other types of fare (e.g.: 10 trip vouchers, single tickets) may be used.

Although the forecast for the future is a slowdown after the strong impulse in 2007, the Madrid region is developing two new projects for the spring of 2011:

- ML5 Valdemoro - circular line. This line, which will link the suburban Valdemoro station (line C-3) to the new Infanta Elena Hospital, will be $10.1 \mathrm{~km}$ long and has 18 stations. It will be a 
circular line, with an important part running through the current city centre. One section will be built in the new neighborhoods, linking them to the rest of the city.

- ML6 Pozuelo de Alarcón - Majadahonda - Las Rozas. The beginning of the line will connect to the Pinar de las Rozas suburban station (lines C-8 and C-10). From there, it will go through the municipal district of Majadahonda to Pozuelo, completing an itinerary of around 21.3 kilometers. Aside from the three towns, the line will serve the new residential developments and will connect to the new Puerta de Hierro Hospital and the ML2 line.

\section{ML1 "Pinar de Chamartin - Las Tablas"}

The ML1 Pinar de Chamartin - Las Tablas line in Sanchicharro and Las Tablas connects these two new urban areas in the north of Madrid, with around 25,000 new homes, to the Metro network.

In 2003, the CRTM prepared a feasibility study on providing transport links from the new urban developments in Las Tablas and Sanchicharro to the north of Madrid City. Land use planning for these areas, and the awaited needs of mobility, led to the proposal of a LRT system which provides intermediate capacity while affording a flexible design, a high degree of integration into the urban environment and excellent accessibility.

In 2006, the Madrid regional government took the decision to build this infrastructure using private funding, holding a tender for the construction and 30-year operating concession. In July 2006, the regional government awarded the concession to Metros Ligeros de Madrid, S.A., which has the following ownership structure: $42.5 \%$ Metro de Madrid, S.A. (a public subway operator); $42.5 \%$ Global Vía Infraestructuras (GVI); and 15\% ALSA (a public transport operator). GVI was incorporated as a joint venture between FCC (a building company) and Caja Madrid savings bank. As part of this company's ownership structure, it was agreed that the line should be operated and maintained by Metro Madrid.

ML1 was the first LRT line that started to operate in Madrid Region. It came into service in May 2007. ML1 connects to Madrid Metro lines M1 and M4 in Pinar de Chamartin, and with Metro line M10 in Las Tablas (see Figures 2 and 3). This mode of transport has a total length of $5.4 \mathrm{~km}$. Along $1.7 \mathrm{~km}$ overground, it conjures up the history and nostalgia of the trams which transported people around Madrid until 1972, while affording the modernity and safety of an environment-friendly system.

Line ML1 has 8 sets of CITADIS 302-TGA rolling stock, with a commercial speed of $21 \mathrm{~km} / \mathrm{h}$ and an Automatic Train Protection (ATP) system. The route from Las Tablas to Pinar de Chamartin takes 15 minutes. The demand has steadily increased since the line was opened. The number of passengers increased to $41 \%$ in 2008 .

The Concessionaire Company earns revenue from the CRTM through a technical fare set in the tender (per passenger carried with a valid ticket). CRTM also monitors line operation in real time from the Public Transport Management Centre (PTMC) that coordinates the operation of all transport systems in the autonomous region of Madrid.

\section{ML2 "Colonia Jardín - Estación de Aravaca" and ML3 "Colonia Jardín - Puerta de Boadilla"}

In northwest of Madrid, two LRT lines link the cities of Pozuelo de Alarcón (the line begins in Estación de Aravaca station) and Boadilla del Monte to Madrid City's Metro network (see Figures 2 and 4). With a combined length of $22.4 \mathrm{~km}$, the two lines, ML2 and ML3, connect to one of the world's largest subway networks at the Colonia Jardín station. Both lines serve up to 120,000 residents in two cities of the northwest area: Pozuelo de Alarcón and Boadilla del Monte, with a population of 80,000 and 40,000, respectively.

These lines cover an extensive area with businesses, services, entertainment areas, commercial and shopping centers, schools and large residential neighborhoods.

In July 2006, Metro Ligero Oeste, S.A. was awarded a 30-year concession to build and operate the two new lines. Its shareholders consist of: 51\% OHL (a construction holding); 30\% Ahorro Corporación (financial institutions and banks); 18.6\% COMSA (a construction and railway transport company); and $0.4 \%$ TRANSDEV (a transport operator). The Concessionaire Company oversees operation and maintenance with a team of 170 employees. 
The construction work for this infrastructure was coordinated through the local governments of Pozuelo de Alarcón, Boadilla del Monte and Alcorcón, which also collaborated on tracing determination in order to better adjust to the actual requirements of residents and future urban planning developments in these cities. All the stations were designed for passengers of any age and with any needs, and are easily accessible to wheelchairs, strollers and bicycles. Underground stations provide escalators, stairways and elevators.

Lines ML2 and ML3 have 27 sets of CITADIS 302-TGA rolling stock, with 100\% low floor, each with capacity for 186 passengers ( 54 seats and 3.5 standing passengers per sq $\mathrm{m}$ ). The commercial speed is $24 \mathrm{~km}$ per hour for ML2 and $25 \mathrm{~km}$ per hour for ML3.

The Concessionaire Company earns revenue from the CRTM via a technical fare set in the tender per passenger with a valid ticket. Supervision and traffic control on both lines is managed from a Control Center located at the depots in Pozuelo de Alarcón. The Control Center performs the following functions: traffic management, operational management of agents, customer information, interaction with security, supervision and system control agents, as well as communication with supervisors of rolling stock and fixed facilities management. All operations are monitored in real time from the CRTM's PTMC.

The ML2 Colonia Jardín - Estación de Aravaca line in Pozuelo de Alarcón is a cross-line on the western edge of the city, providing transport connections to residential areas, offices and the University Complutense of Madrid (Somosaguas Campus). At one end it connects to the Metro and another LRT line (M10 and ML3) and at the other it connects to the suburban railway (lines C-7 and C-10) (see Figure 4). Journey time between Colonia Jardín and the Aravaca Station is 22 minutes, with 13 stations (3 underground) and a length of $8.7 \mathrm{~km}$. In 2008 the demand increased more than $18 \%$.

The ML3 Colonia Jardín - Puerta de Boadilla line in Boadilla del Monte and part of Pozuelo and Alcorcón is a radial line that crosses two of the city's rings, starting from a Metro station and LRT line (M10 and ML2), to connect leisure, office and university areas, and ending at Boadilla del Monte (see Figure 4). Travel time between Colonia Jardín and Puerta de Boadilla is 32 minutes, with 16 stations (1 underground) and a length of $13.7 \mathrm{~km}$.

\section{ML4 "Parla Tramway"}

The circular ML4 line in Parla is a highly urban line which goes through the centre of town and connects to a suburban railway station to give access to new residential areas, such as East Parla, and a new suburban rail station (North Parla), which has yet to open (see Figure 5).

Parla is located in the southern part of Madrid Region. Although it is $20 \mathrm{~km}$ from Madrid, it has a close relationship with the city. Prior to the 1970 s, Parla was a mere village, a farming town of only 2,000 inhabitants, but over the past 40 years the town has undergone an important population transformation. Currently, it is a commuter town with a population of over 115,000.

Recently, Parla is facing large-scale urban development (East Parla, with 12,000 new homes) and industrial development (a Business Park, covering close to 6 million square meters), which are causing drastic changes in the town's urban structure. The new developments have forced the CRTM to outline a new Transport Plan to extend city bus lines and reconfigure suburban bus lines, and to implement a mode of transport providing greater capacity: the Parla Tramway.

In February 2005, the CRTM held a tender for project design, financing, construction, acquisition of rolling stock and operation and maintenance of the line during a 40-year period. In June of the same year, the concession was awarded to Tranvía de Parla, S.A., comprising Global Vía Infraestructuras (GVI) (85\%) and Caja de Castilla La Mancha savings bank (15\%).

On June 5, 2007, the first phase of this line went into service with 9 stations and 4.25 kilometers of track, providing service to Parla city center. The second phase of the tram began operation on September 8 of the same year, connecting the new residential areas of East Parla with the city center and other key areas along 3.25 kilometers with 6 stations. Finally, the line commenced operations as a circular line on May 21, 2008.

The line operates with 9 sets of CITADIS 302 rolling stock, with a commercial speed of $21 \mathrm{~km} / \mathrm{h}$, and 23 minutes, in average, for a round trip. Service interval at peak hours is 7 minutes in either direction, 
to adjust the schedule as closely as possible to the suburban service on an average working day. The successive expansions, along with the attractiveness of the new mode of transport, have led passenger numbers to double during the first year of service.

The circular ML4 line, in addition to facilitating mobility within Parla, links to urban and interurban bus networks as well as to the suburban railway network (current suburban rail station, Center Parla (line C-4), and the planned one, North Parla).

One of the most interesting aspects of the plan is the fact that $33 \%$ of capital investment came from land value capture raised by the East Parla Land Development Consortium. The remaining 67\% will be paid annually by the Parla municipality. Regarding the system operation, Parla local government and the CRTM have agreed to compensate (50\% each) the deficit arising from the market equilibrium fare/passenger, fixed in the concession contract (4).

\section{CONCLUSIONS AND RECOMMENDATIONS}

This brief overview demonstrates the versatility of the LRT systems in the suburbs of big cities such as Madrid. The principal aspects worth highlighting are:

Planning and operation LRT systems:

- The system meets transport needs in medium-density urban areas and towns with a medium demand for transport. Furthermore, the system's layout needs to go through key high-demand areas (hospitals, shopping centers, business areas and new or important residential developments) to justify construction costs.

- The commercial speed of LRT is not very fast (20-25 km per hour), compared to subways and suburban railways, so the lines should not be too long (no more than $15 \mathrm{~km})(2,5)$. This recommendation matches the length of the lines studied, which are 5-14 km long. This keeps journey times within intermediate values (30-45 min.) that can compete with private vehicles (Madrid LRT journey times are 15-32 minutes). That commercial speed requires the longest possible segregated right-of-way and a distance between stops of more than 500 meters (6). This is a crucial aspect for LRT systems and requires a maximum agreement and coordination between all the authorities involved. For this reason they are highly appropriate in new urban developments with wide streets.

- Other key aspects to ensure the success of the new LRT systems include attractive, fully accessible rolling stock (taking vehicle safety and comfort and the level of occupation into consideration, for instance). The recommendation for the transport capacity to adopt when planning LRT lines is to base capacity on the maximum recommended occupation (based on the quality of other existing transport modes), rather than considering directly the capacity indicated by rolling stock manufacturers (based on standing passengers per sq $\mathrm{m}$ ). The higher the quality of alternative public and private transport, the lower the maximum recommended occupation used should be. Thus, LRT quality is increased, as well as the potential for capturing new passengers. The LRTs being implemented in the Madrid region are considering less occupation than rolling stock manufacturers recommend, taking 3.5 standing passengers per sq $\mathrm{m}$ at peak times instead of 4 standing passengers per sq $\mathrm{m}$ recommended by the manufacturers. The recommendation also takes into account that, even when signal priority is used, the frequency in segregated right-of-way systems can hardly be less than three minutes without jeopardizing quality of service due to traffic incidents and so on. Thus, for a vehicle capacity of 250 passengers and a frequency of 20 vehicles $/ \mathrm{hr}$, maximum LRT capacity under conditions of maximum recommended capacity is 5,000 passengers per hour and direction (6).

- Another key aspect is the need for LRTs to be well linked (via transport interchanges) and coordinated (at the schedule and fare levels) with other public transport networks (subways, suburban railways, city buses, suburban buses and so on). Therefore, LRT planning should be done in such a way that it will feed other transport modes with a higher capacity (e.g.: ML1 feeds Metro lines M1, M4 and M10; ML2 feeds Metro line M10, suburban railway lines C-7 
and C-10, and also links to ML3; ML3 also feeds M10 and links to ML2; and ML4 feeds the C-4 suburban railway line). Furthermore, LRT management should be integrated into the regional transport authority. Thus, CRTM monitors and coordinates the LRT lines in real time with the entire public transport system. The coordination should be done whether the operation is public (ML1) or private (ML2, ML3 and ML4). Likewise, the LRT fare system should be the same as for other modes of public transport. Typically, this implies the need for subsidies due to the fact that the technical fare tends to be higher than the passenger fare. Funding can be covered with public funds from the administrations involved (e.g.: regional or local governments) or via the property taxes generated by new urban developments along the way (as in the Parla Tramway) (4).

Taking financial aspects into consideration, there are several relevant aspects:

- The BOT (build-operate-transfer) method was used in all of the cases studied and in most of the projects developed in Spain (5). The BOT is a concessionaire model that distributes risk between the administration and the private sector. This gets the private sector involved in funding, thereby preventing budget limitations, and integrates their experience into management (7). At the same time, it puts a limit on the risk assumed by stakeholders in projects that are included in a complex urban context and with interactions that are difficult to control.

- Shen et al. (8) establish that the concession period is one of the most important decisions to be made when the BOT contract is applied to infrastructure projects. The duration of the concession period directly affects both the investor's level of return on the investment and the government's interests. In the Madrid region, as in other projects in Spain, time periods vary from 30 to 40 years.

- In the 4 new LRT lines described, the consortiums that were awarded the BOT mainly comprise builders, transport operators and financial institutions. Consultants and rolling stock manufactures are the other stakeholders who have not yet become partners in Spanish consortiums but who carry out key functions so the system will run smoothly by supplying rolling stock, integrating systems, preparing tenders, projects, operation consultancy and so on (5). In the foreseeable future, they will probably become partners in the consortiums as stakeholders, albeit with a small stake.

LRT systems also have a notable impact on citizens and the city itself, as political leaders are quick to realise:

- Important aspects worthy of mention are the possibility of using the implementation of an LRT line to remodel and recover substandard urban areas, and to give pedestrians more space by taking it away from private vehicles (1). All of the above aspects make LRT systems very attractive and flexible modes of transport. Many cities have turned to light rail transit lines instead of building conventional subways to develop their transport networks (2).

- Lower costs, faster building periods (1-3 years in Madrid's lines) and a less negative impact on residents during construction (less extensive building sites) are other aspects that may encourage the implementation of LRTs instead of subways and suburban railways. These advantages should not be a determining factor if the optimal solution is a system with more capacity. The fact that using an LRT to extend a subway or a suburban railway line always implies a passenger interchange, to the detriment of capturing demand, should also be taken into consideration. On the other hand, the limited execution period is a very tempting prospect for local authorities (in Spain, political positions are held for four years). Politicians realize that LRTs can be completed during their term, as opposed to the Metro and suburban railways, which take longer to complete. Finally, the freedom to plan, finance, construct and operate LRT lines compared to suburban railways (managed by the Public Works Ministry through RENFE) can also tip the balance towards LRT.

Finally, a recent study (9) identified three key features that justify the success of the LRT system in Portland and in four other U.S. cities where LRT carries $30 \%$ or more of all metropolitan area transit 
riders: dispersed transit network, that it is structured to serve an array of major destinations throughout the entire metropolitan area (e.g. hospitals, business center, etc.); high-speed regional service atop the local bus system; and easy transfer LRT and the bus and rail systems. All these characteristics are in the new LRT lines in Madrid region, but there are also some other features that have been introduced by this paper and that could be applied for better planning of regional and suburban transit services:

$\circ$ Lines that are not very long

- The longest segregated right-of-way possible

- Capacity considerations based on the maximum recommended occupation

- Coordination of schedules and fares with other modes of public transport

$\circ$ The possibility of funding via property tax

- The convenience of public-private partnership (via BOT or similar systems) in funding and management to distribute risk between several stakeholders

- A 30-40 year concession period

- Consortiums comprising builders, operators, financiers, rolling stock manufacturers and consultants

- The possibility of using LRT implementation to remodel and recover substandard urban areas.

\section{ACKNOWLEDGEMENTS}

The authors would like to thank Jesús Rodríguez Molina for his personal contribution to this paper.

\section{REFERENCES}

1. Priemus, H. and Konings, R. Light rail in urban regions: What Dutch policymakers could learn from experiences in France, Germany and Japan. Journal of Transport Geography, Vol. 9 (3), 2001, pp. 187-198.

2. ERRAC. Light Rail and Metro systems in Europe: Current market, perspectives and research implication. European Rail Research Advisory Council, Brussels, 2004.

3. CRTM. Light Rails and Tramways in Madrid Region. $2^{\text {nd }}$ Edition. Consorcio Regional de Transportes de Madrid, Madrid, 2009.

4. De Marcos, F., Rodriguez, J. and Gonzalez, J.D. Tranvía de Parla, un referente. Proceedings of the VIII Congreso de Ingeniería de los Transportes, A Coruña, 2-4 July 2008.

5. Sastre, J. New concessions of light rail transit: Public and private partnership, management and funding model comparison. PhD Thesis, Polytechnic University of Madrid, 2009. Available on line: http://oa.upm.es/1660/

6. Cristobal, C. Reflexiones sobre los modos de transporte público en las ciudades. Ingeniería y Territorio, Vol. 86, 2009, pp. 32-39.

7. Fayard, A. and Bousquet, F. Pragmatic Approach to Finance Infrastructure Analysis of French Experience with Highway Concessions. Transportation Research Record, Vol. 1649, 1998, pp. 9-16.

8. Shen, L.Y., Li, H. and Li, Q.M. Alternative Concession Model for Build Operate Transfer Contract Projects. Journal of Construction Engineering \& Management, Vol. 128 (4), 2002, pp. 326-330.

9. Thompson, G.L. and Brown. J.R. Making a Successful LRT-Based Regional Transit System: Lessons from Five New Start Cities. Transportation Research Record, 2009, in press. 


\section{List of Tables}

TABLE 1 General figures in Europe

TABLE 2 Population, surface area and density in the Madrid region

TABLE 3 Modal split for mechanized mobility

TABLE 4 Public transportation system: supply and demand (2008)

TABLE 5 Key information on Madrid Region LRT on-service lines 


\section{List of Figures}

FIGURE 1 Example of urban integration and LRT vehicle in Madrid region

FIGURE 2 Map of Metro and LRT lines in the Madrid region

FIGURE 3 ML1 Pinar de Chamartin - Las Tablas

FIGURE 4 ML2 Colonia Jardín - Estación de Aravaca and ML3 Colonia Jardín - Puerta de Boadilla FIGURE 5 ML4 Parla Tramway 
TABLE 1 General figures in Europe (2)

\begin{tabular}{|l|c|c|c|}
\hline & Systems & Lines & Track length $(\mathbf{k m})$ \\
\hline EU-15 & 107 & 448 & $4,793(69 \%)$ \\
\hline New Member States & 30 & 349 & $2,240(28 \%)$ \\
\hline Beyond EU-25 & 33 & 144 & $1,027(13 \%)$ \\
\hline TOTAL & $\mathbf{1 7 0}$ & $\mathbf{9 4 1}$ & $\mathbf{8 , 0 6 0}$ \\
\hline
\end{tabular}


TABLE 2 Population, surface area and density in the Madrid region (3)

\begin{tabular}{|l|c|c|c|c|}
\hline & Municipalities & $\begin{array}{c}\text { Population } \\
\mathbf{2 0 0 7}\end{array}$ & $\begin{array}{c}\text { Surface area } \\
\mathbf{( \mathbf { k m } ^ { 2 } )}\end{array}$ & $\begin{array}{c}\text { Density } \\
\left(\mathbf{p o p} / \mathbf{k m}^{\mathbf{2}}\right)\end{array}$ \\
\hline Madrid City Zone A & 1 & $3,213,271$ & 606.4 & $5,298.9$ \\
\hline Metropolitan Zone B & 49 & $2,628,536$ & $2,280.7$ & $1,152.5$ \\
\hline Regional Zone C & 129 & 429,831 & $5,141.4$ & 83.6 \\
\hline TOTAL & $\mathbf{1 7 9}$ & $\mathbf{6 , 2 7 1 , 6 3 8}$ & $\mathbf{8 , 0 2 8 . 5}$ & $\mathbf{7 8 1 . 2}$ \\
\hline
\end{tabular}


TABLE 3 Modal split for mechanized mobility (3)

\begin{tabular}{|l|c|c|}
\hline & $\begin{array}{c}\text { Public } \\
\text { transport (\%) }\end{array}$ & $\begin{array}{c}\text { Private } \\
\text { transport (\%) }\end{array}$ \\
\hline Internal mobility to the city of Madrid & $64 \%$ & $36 \%$ \\
\hline $\begin{array}{l}\text { Radial mobility between the city of Madrid and the rest } \\
\text { of the Madrid region }\end{array}$ & $50 \%$ & $50 \%$ \\
\hline Internal mobility in the rest of Madrid region & $27 \%$ & $73 \%$ \\
\hline Total mechanised mobility & $\mathbf{4 9 . 3 \%}$ & $\mathbf{5 0 . 7 \%}$ \\
\hline
\end{tabular}


TABLE 4 Public transportation system: supply and demand (2008) (Own source, based on 3)

\begin{tabular}{|c|c|c|c|c|c|c|c|}
\hline \multirow[b]{3}{*}{ MODES } & \multicolumn{4}{|c|}{ SUPPLY } & DEMAND & \multicolumn{2}{|c|}{ RATIOS } \\
\hline & A & B & $\mathrm{C}$ & $\mathrm{D}$ & $\mathrm{E}$ & $\mathrm{F}$ & G \\
\hline & $\begin{array}{l}\text { Number } \\
\text { of lines }\end{array}$ & $\begin{array}{l}\text { Length } \\
\text { of lines } \\
(\mathrm{km})\end{array}$ & $\begin{array}{l}\text { Number } \\
\text { of } \\
\text { stations }\end{array}$ & $\begin{array}{l}\text { Number } \\
\text { of } \\
\text { vehicles }\end{array}$ & $\begin{array}{l}\text { Passenger } \\
\text { (millions) }\end{array}$ & $\begin{array}{l}\text { Passenger } \\
/ \mathrm{Km} \text { of } \\
\text { line }(\mathrm{E} / \mathrm{B})\end{array}$ & $\begin{array}{l}\text { Passenger } \\
\text { / Station } \\
(\mathrm{E} / \mathrm{C})\end{array}$ \\
\hline Metro & $12+1$ & 283.3 & 232 & 2,157 & 692.3 & 2.44 & 2.98 \\
\hline EMT urban buses. Zone A & 208 & 3,781 & 10,838 & 2,060 & 425.6 & 0.11 & 0.04 \\
\hline Urban buses. Zones B and C & 129 & 1,857 & 4,314 & $173 *$ & 47.8 & 0.03 & 0.01 \\
\hline Suburban buses. Zones B and C & 330 & 20,030 & 16,981 & $1751 *$ & 220.3 & 0.01 & 0.01 \\
\hline Suburban railway & 9 & 363.2 & 99 & $858 *$ & 197.4 & 0.54 & 1.99 \\
\hline Light Rail & 4 & 36 & 53 & 44 & 14.8 & 0.41 & 0.28 \\
\hline
\end{tabular}

* Data 2007. 
TABLE 5 Key information on Madrid Region LRT on-service lines (3)

\begin{tabular}{|l|c|c|c|c|c|c|c|c|}
\hline Line & $\begin{array}{c}\text { Opening } \\
\text { date }\end{array}$ & $\begin{array}{c}\text { Frequency } \\
\text { in Peak } \\
\text { Hour }\end{array}$ & $\begin{array}{c}\text { Length } \\
\mathbf{( k m )}\end{array}$ & $\begin{array}{c}\text { Stations } \\
\text { (number) }\end{array}$ & $\begin{array}{c}\text { Rolling } \\
\text { Stock } \\
\text { (units) }\end{array}$ & $\begin{array}{c}\text { Construction } \\
\text { Investment } \\
\text { (M€) }\end{array}$ & $\begin{array}{c}\text { Investment } \\
\text { / km (M€) }\end{array}$ & $\begin{array}{c}\text { Passengers } \\
\mathbf{2 0 0 8} \\
\text { (millions) }\end{array}$ \\
\hline ML1 & may 24, 2007 & 5 min. & 5.4 & 9 & 8 & 254.0 & 47.0 & 4.2 \\
\hline ML2 & july 27, 2007 & 6 min. & 8.7 & $13+1^{*}$ & 12 & 260.0 & 29.9 & 3.4 \\
\hline ML3 & july 27, 2007 & 6 min. & 13.7 & $16+3^{*}$ & 15 & 262.2 & 19.1 & 3.5 \\
\hline ML4 & june 05, 2007 & 7 min. & 8.2 & $15+1^{*}$ & 9 & 128.2 & 15.6 & 3.7 \\
\hline TOTAL & & $\mathbf{3 6 . 0}$ & $\mathbf{5 3}$ & $\mathbf{4 4}$ & $\mathbf{9 0 4 . 4}$ & $\mathbf{2 5 . 1}$ & $\mathbf{1 4 . 8}$ \\
\hline
\end{tabular}

* Theses stations will open in phase II 


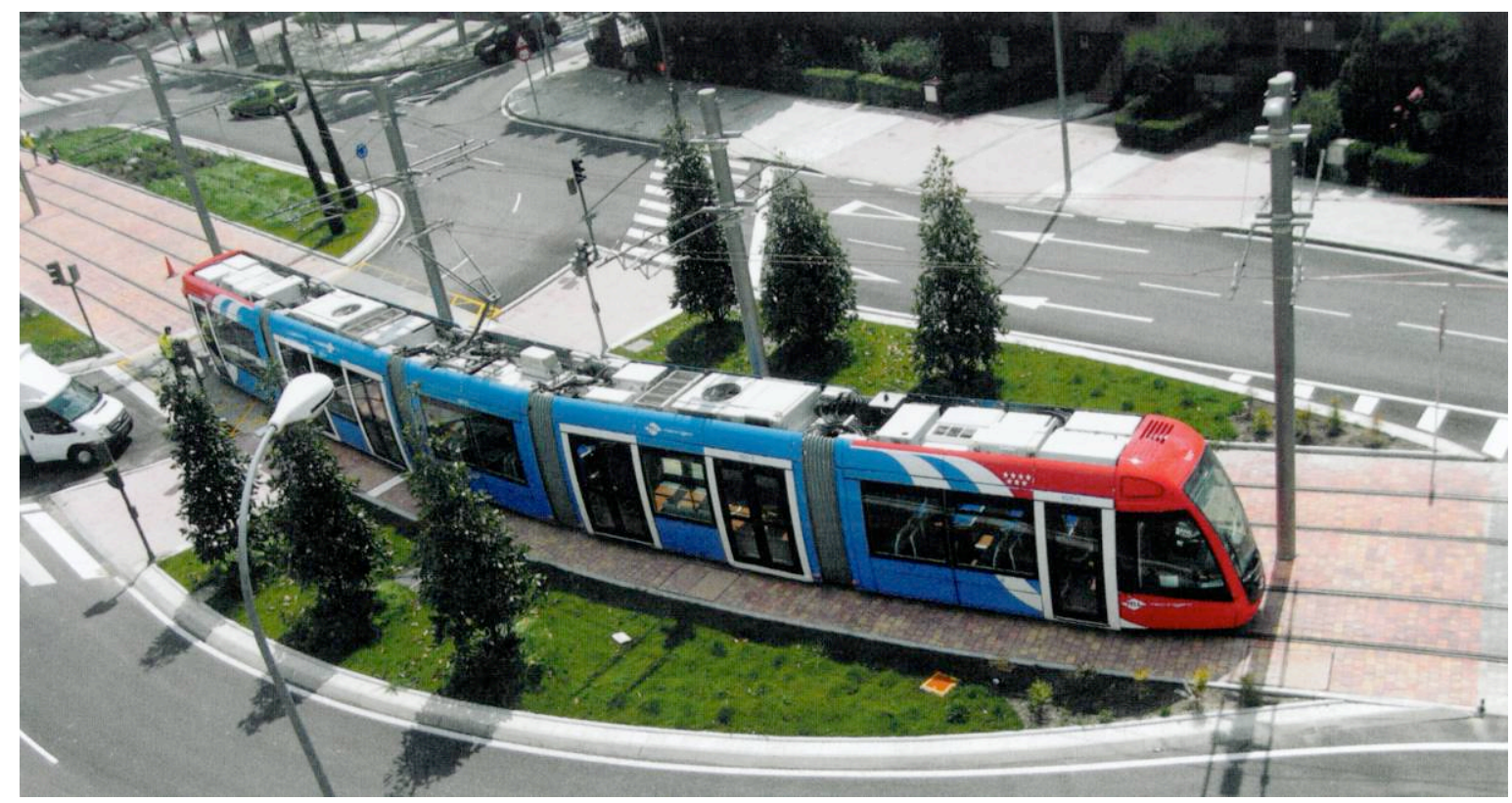

FIGURE 1 Example of urban integration and LRT vehicle in Madrid region 


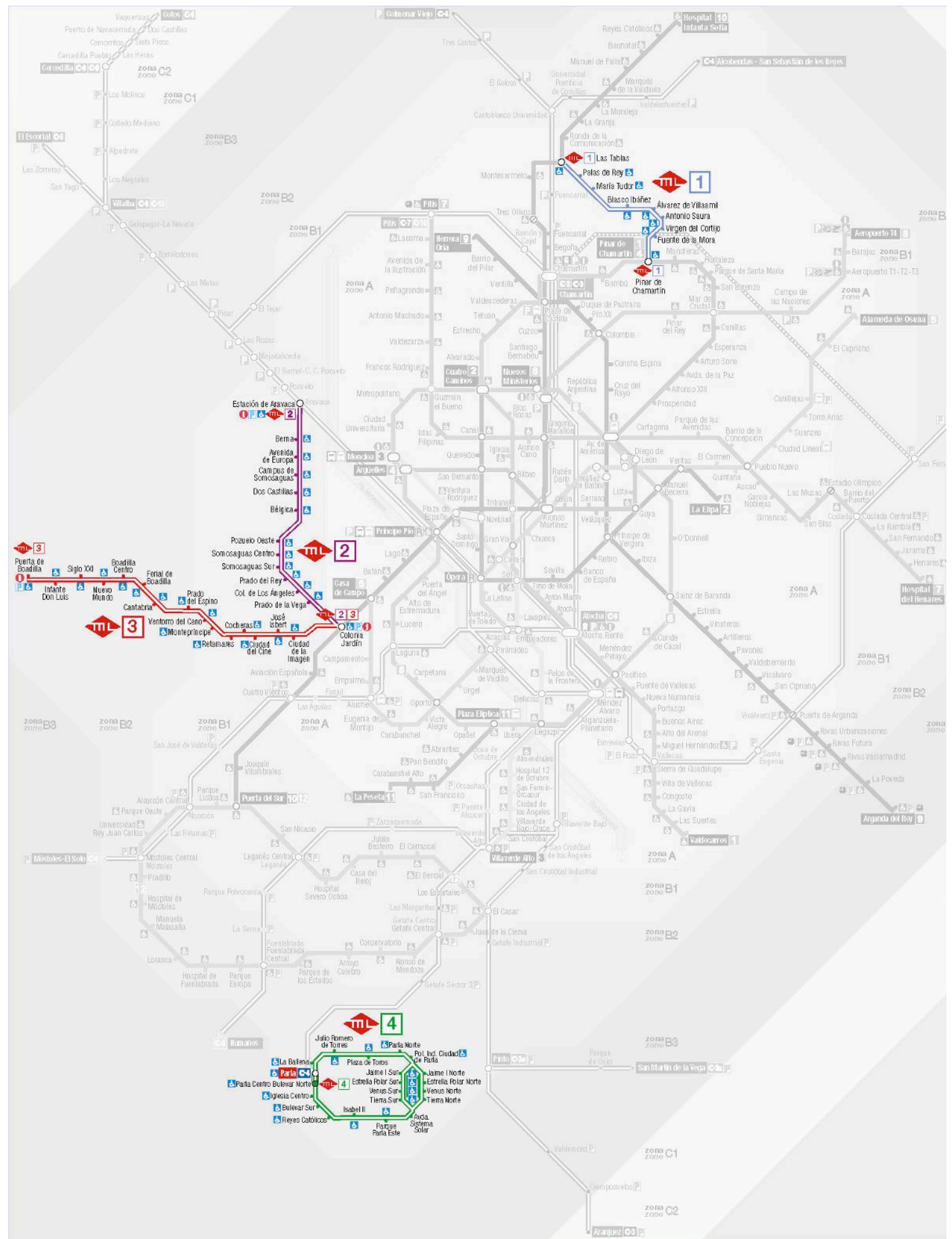

FIGURE 2 Map of Metro and LRT lines in the Madrid region. Source: www.metromadrid.es 


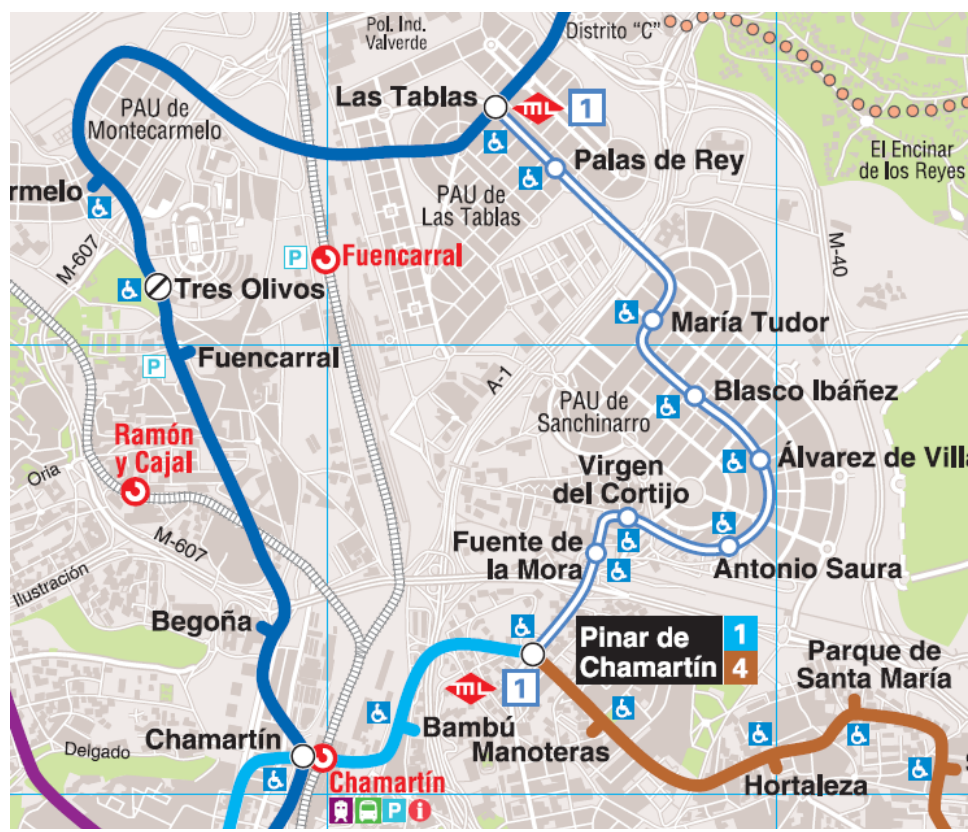

FIGURE 3 ML1 Pinar de Chamartin - Las Tablas. Source: www.melimadrid.es 


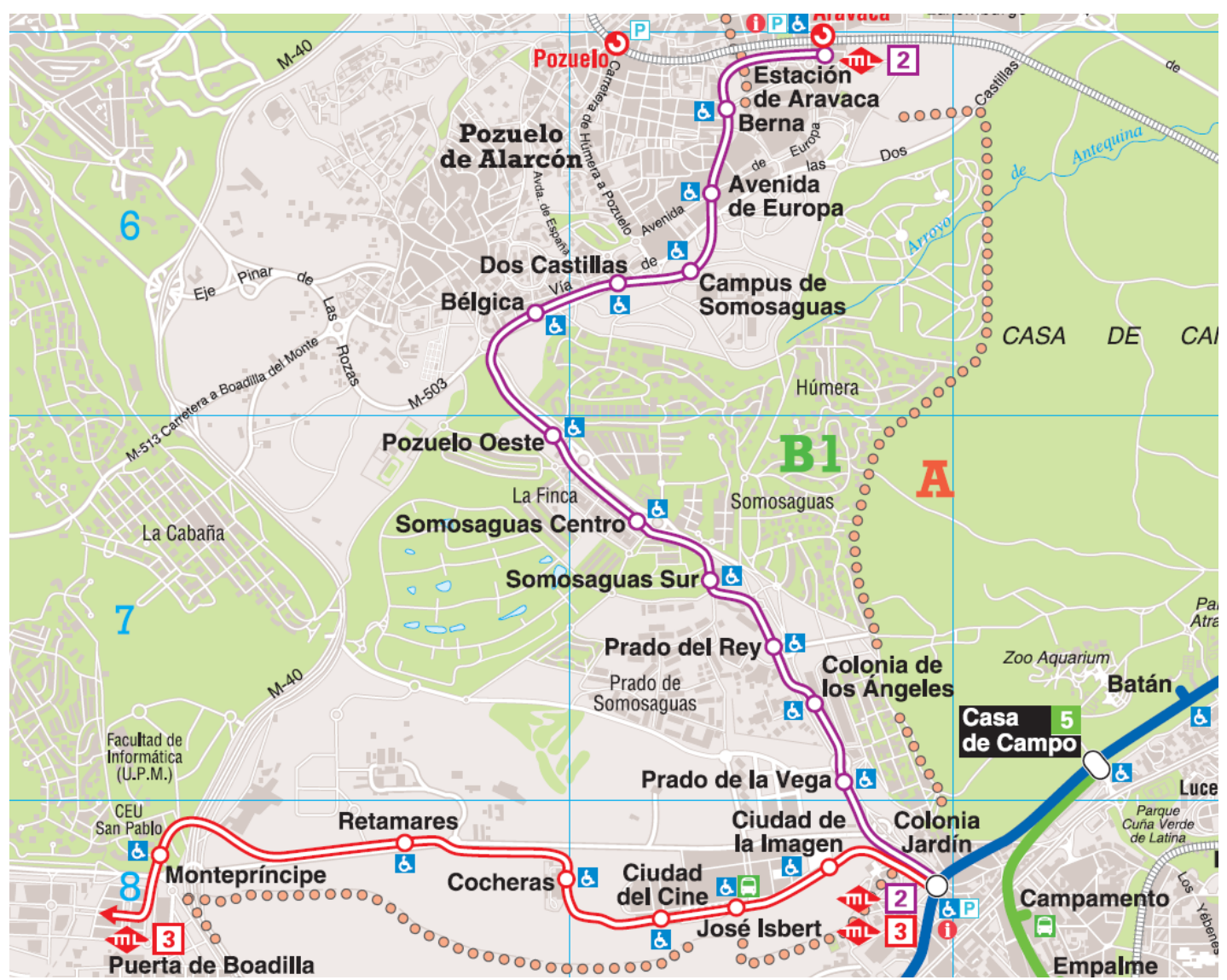

FIGURE 4 ML2 Colonia Jardín - Estación de Aravaca and ML3 Colonia Jardín - Puerta de Boadilla. Source: www.metroligero-oeste.es 


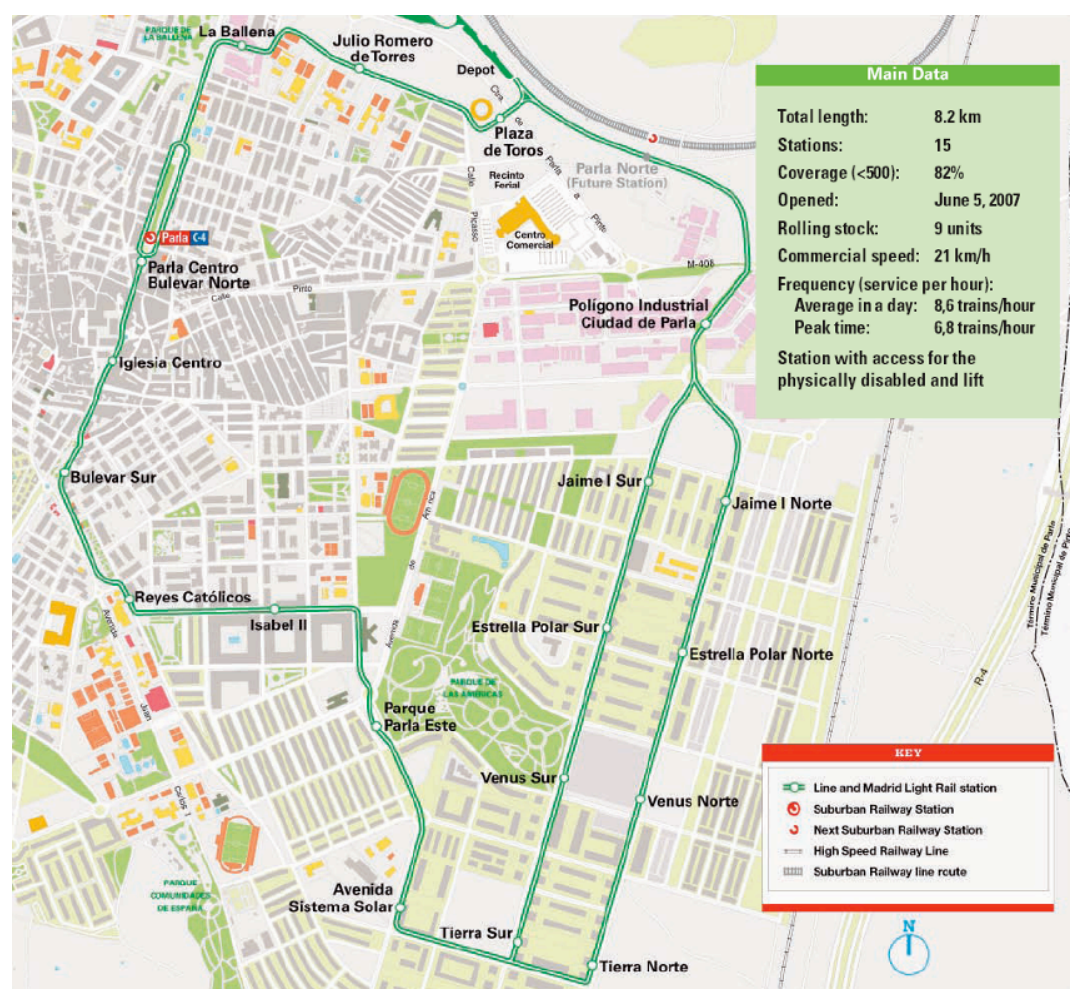

FIGURE 5 ML4 Parla Tramway. Source: www.viaparla.com 